\title{
Compressive Mechanical Properties of a Novel Recycled Aggregate Concrete with Recycled Lightweight Aggregate
}

\author{
Anjun Li, ${ }^{1}$ Gaoqiang Zhou, ${ }^{2}$ Xianggang Zhang $\mathbb{D}^{2},{ }^{2}$ and Ercong Meng ${ }^{1}$ \\ ${ }^{1}$ School of Engineering and Technology, Southwest University, Chongqing 400715, China \\ ${ }^{2}$ School of Civil Engineering, Henan Polytechnic University, Jiaozuo 454003, China \\ Correspondence should be addressed to Xianggang Zhang; xgzhang1986@163.com
}

Received 29 July 2021; Revised 20 October 2021; Accepted 2 November 2021; Published 20 November 2021

Academic Editor: Shazim A. Memon

Copyright $\odot 2021$ Anjun Li et al. This is an open access article distributed under the Creative Commons Attribution License, which permits unrestricted use, distribution, and reproduction in any medium, provided the original work is properly cited.

A novel recycled aggregate concrete was prepared by replacing the natural aggregate with recycled lightweight aggregate. Subsequently, the mechanical properties and compressive stress-strain constitutive relation of the recycled lightweight aggregate concrete (RLWAC) were explored. For this purpose, the recycled lightweight aggregate (RLWA) replacement ratio $(0 \%, 25 \%, 50 \%$, $75 \%$, and 100\%) was selected as a variable, and the compressive strength of 15 cube and 30 prism specimens was evaluated. The failure morphology of the specimen was subsequently characterized, along with the cubic compressive strength, axial compressive strength, peak strain, ultimate strain, and other performance indices. The influence of the replacement ratio for the specimen indices of the RLWAC was also analyzed. It was observed that the dry apparent density of RLWAC decreased gradually on increasing the replacement ratio. Compared with $0 \%$ replacement ratio, a decrease of $6.50 \%, 11.39 \%, 21.84 \%$, and $27.54 \%$ was observed, respectively. On enhancing the RLWA replacement ratio, the compressive strength, peak strain, and ultimate strain of RLWAC were observed to be gradually reduced. As the replacement ratio was increased from $75 \%$ to $100 \%$, the peak strain was noted to decrease the most by about $6.8 \%$. As the replacement ratio was increased from $50 \%$ to $75 \%$, the ultimate strain decreased the most by about $14.2 \%$. Based on the experimental findings, the functional relationships of the strength indices and the conversion value of each strength index with the replacement ratio were also established. Finally, based on the model proposed by the existing model, the stress-strain equation of RLWAC was developed, and the fitting results were observed to be in good agreement with the test results.

\section{Introduction}

Owing to the piling of construction waste in China, the effective use of the waste has become a serious concern $[1,2]$. In this respect, after the construction waste is crushed and graded, a fraction (or even all) of the natural coarse and fine aggregates can be replaced as per the specific composition. Subsequently, water and cement can be added to form recycled aggregate concrete (RAC) [3-5]. The recycling of waste concrete not only significantly reduces the consumption of natural resources and alleviates the pressure on the increasingly scarce resources, but it also has a more practical significance for protecting the environment $[6,7]$. However, the sources of the recycled coarse aggregate in the recycled concrete are relatively extensive. In previous studies
[8-10], the recycled coarse aggregate has been mostly derived from ordinary concrete; however, the RLWA produced from the RLWAC structures after dismantling has not been explored in detail $[11,12]$. Lightweight aggregate concrete (LWAC) is mainly composed of porous lightweight aggregate or artificial ceramsite as the coarse aggregate, in which the dry apparent density is not higher than $1950 \mathrm{~kg} /$ $\mathrm{m}^{3}$. LWAC has the characteristics of lightweight structure, superior deformation performance, and heat preservation [13]; thus, the weight of the structure is reduced and materials are saved $[14,15]$. As a result, LWAC is mainly used in large-span bridges, high-rise buildings, roadbeds, and pavement. As a source of construction waste, LWAC can achieve resource utilization of RLWAC construction waste through RAC technology [16-18]. RLWAC is a novel 
concrete made up of the waste LWAC after mechanical or artificial crushing, screening, grading, and other processes in accordance with the designed proportion attained by partially or completely replacing the natural coarse aggregate (NCA). Moreover, adding RLWA to ordinary concrete not only inherits the advantages of LWAC, such as low selfweight, excellent thermal performance, and optimal seismic characteristics [19-21], but also improves the low strength, poor elastic modulus, and other mechanical properties of LWAC [22, 23].

At present, the research on the performance index of the RLWAC and stress-strain equation (full curve) is in the preliminary stage [24, 25]. Wongkvanklom et al. [26] studied the influence of the RLWAC replacement ratio on the properties of structural lightweight concrete. The results showed that structural lightweight concrete containing 25\%, $35 \%$, and $45 \%$ RLWA had a 28 -day compressive strength of $30.3,19.8$, and $16.5 \mathrm{MPa}$, respectively. Thus, only $45 \%$ of the RLWA replacement ratio was observed to exhibit lower performance than the requirement. Huang et al. [27] studied the microstructure of RLWAC, and four types of interfacial transition zones (ITZ) were observed between the cement paste and lightweight aggregate of RLWAC. The ITZ between the new mortar and RLWA covered with the old mortar was noted to be the weakest, whereas the ITZ between the new mortar and RLWA with no coverage of the old mortar was the strongest. Bogas et al. [28] studied the effect of the RLWA replacement ratio on the concrete characteristics. It was observed that after replacing the lightweight aggregate with RLWA, the compressive strength and splitting tensile strength increased by up to $14 \%$ and $32 \%$, respectively. Bogas et al. [29] also studied the influence of RLWA on the long-term performance of concrete. As observed, the incorporation of RLWA enhanced the carbonation and chloride ion penetration resistance of the nonstructural LWAC, and the increment of the carbonation resistance and coefficient of diffusion varied up to $70 \%$ and $20 \%$, respectively. Kazmi et al. [30] proposed a new compression casting RAC approach, and the compressive strength and elastic modulus of the compressed RAC specimens were observed to be higher than the uncompressed RAC specimens. Munir et al. [31] established a general axial stress-strain model of the steel spiral confined normal aggregate concrete, RAC, and treated RAC, which exhibited optimal applicability and could determine the permissible content of RCA. Overall, domestic and foreign scholars are mostly focused on RAC and LWAC research, and the study of RLWAC is still in its infancy. Due to RLWAC's advantages of reducing the structural weight and saving natural aggregate, it has a wide application prospect, thus requiring further study $[32,33]$.

In this study, the compressive strength of RLWAC was characterized, and the influence of the replacement ratio of the RLWA on the compressive strength, peak stress, peak strain, and other performance indices was discussed. The functional relationships of the strength indices and conversion value of each strength index with the replacement ratio were also established. Finally, the stress-strain equation of the RLWAC was developed.

\section{Test Program}

2.1. Materials. P.O 42.5 ordinary Portland cement was selected in this study. Ordinary tap water was used as the mixing water. The continuous graded gravel was employed as the natural coarse aggregate, with the particle size ranging between 5 and $31.5 \mathrm{~mm}$. The recycled lightweight coarse aggregate was obtained by the artificial crushing, grading, screening, and drying of the waste shale ceramsite LWAC specimen with LC20 and LC25 grades from the structural hall of Henan Polytechnic University. The crushed RLWA was uniformly mixed at a volume ratio of 1 : 1 , with the particle size ranging between 5 and $31.5 \mathrm{~mm}$. The maximum size of the coarse aggregates was $31.5 \mathrm{~mm}$. The particle size distribution (China, GB/T 17431.1-2010) is presented in Figure 1, and the coarse aggregates are shown in Figures 2(a) and 2(b), respectively. Furthermore, the basic physical properties are presented in Table 1. As observed, the water absorption ratio of the RLWA was determined to be $9.46 \%$, which is much higher than that of the natural coarse aggregate. It is due to the reason that the surface of the RLWA is rough, with numerous internal pores. The measured concrete mixture exhibits optimal workability, and the collapse degree lies in the range of $170 \mathrm{~mm}-190 \mathrm{~mm}$.

2.2. Design of Mixture Proportions. The replacement ratio of the RLWA was varied as $0 \%, 25 \%, 50 \%, 75 \%$, and $100 \%$ (weight percentage of the RLWA to the total coarse aggregate). The specimen with a $0 \%$ replacement ratio acted as a benchmark, and the benchmark mixture proportion was $440 \mathrm{~kg} / \mathrm{m}^{3}$ of cement, $1066.32 \mathrm{~kg} / \mathrm{m}^{3}$ of natural coarse aggregate, $0 \mathrm{~kg} / \mathrm{m}^{3}$ of recycled lightweight coarse aggregate, $634.08 \mathrm{~kg} / \mathrm{m}^{3}$ of sand, $208 \mathrm{~kg} / \mathrm{m}^{3}$ of net water, $0 \mathrm{~kg} / \mathrm{m}^{3}$ of additional water, and an effective water-binder ratio of 0.47 (the effective water-binder ratio is the quality ratio of net water to cement). The amount of the other materials remained unchanged. By changing the amount of the natural coarse aggregate, recycled lightweight coarse aggregate, and additional water, the specimens with replacement ratios of $25 \%$, $50 \%, 75 \%$, and $100 \%$ were developed. The amount of the natural aggregate was $799.74 \mathrm{~kg} / \mathrm{m}^{3}, 533.16 \mathrm{~kg} / \mathrm{m}^{3}, 266.58 \mathrm{~kg} /$ $\mathrm{m}^{3}$, and $0 \mathrm{~kg} / \mathrm{m}^{3}$, respectively. The amount of the recycled lightweight coarse aggregate was $139.68 \mathrm{~kg} / \mathrm{m}^{3}, 279.36 \mathrm{~kg} / \mathrm{m}^{3}$, $419.04 \mathrm{~kg} / \mathrm{m}^{3}$, and $558.72 \mathrm{~kg} / \mathrm{m}^{3}$, respectively. In addition, the amount of additional water was $13.21 \mathrm{~kg} / \mathrm{m}^{3}, 26.43 \mathrm{~kg} / \mathrm{m}^{3}$, $39.64 \mathrm{~kg} / \mathrm{m}^{3}$, and $52.85 \mathrm{~kg} / \mathrm{m}^{3}$, respectively. Overall, 15 cube and 30 prism specimens were used, with 3 cube and 6 prism specimens developed for each replacement ratio.

2.3. Preparation and Loading of Specimens. A pressure testing machine (SYE-2000) with a maximum test force of $2000 \mathrm{kN}$ was used. As per the "Standard for test methods of concrete physical and mechanical properties" (China, GB/ T50081-2019), the cubic and axial compressive strengths were analyzed at a loading rate of $9 \mathrm{kN} / \mathrm{s}$. The recycled lightweight aggregate replacement ratio was used as a variable. Subsequently, 15 cubes with dimensions of 


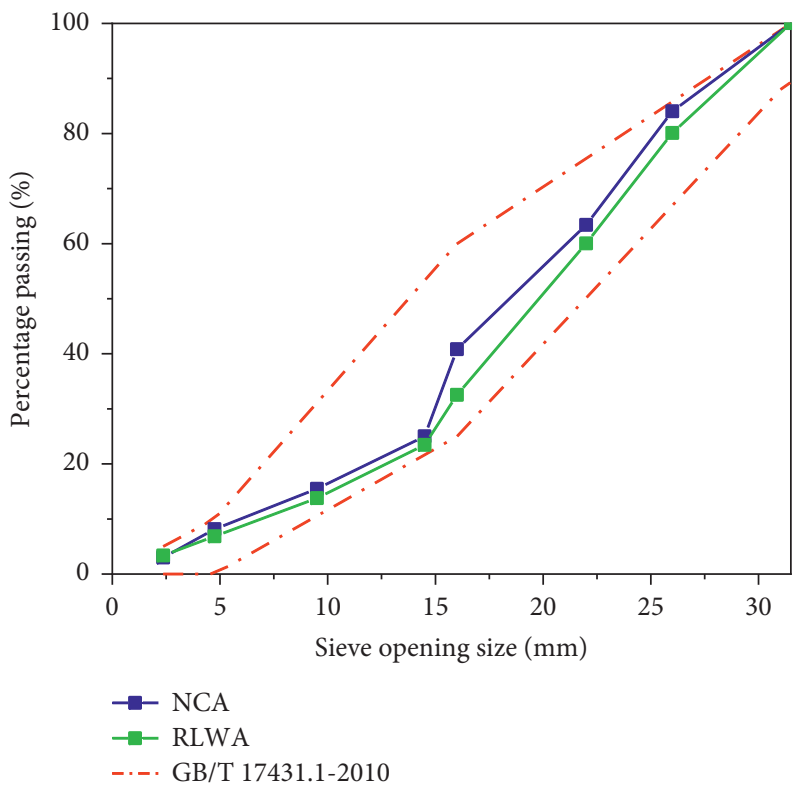

FIGURE 1: Sieve analysis of coarse aggregates.

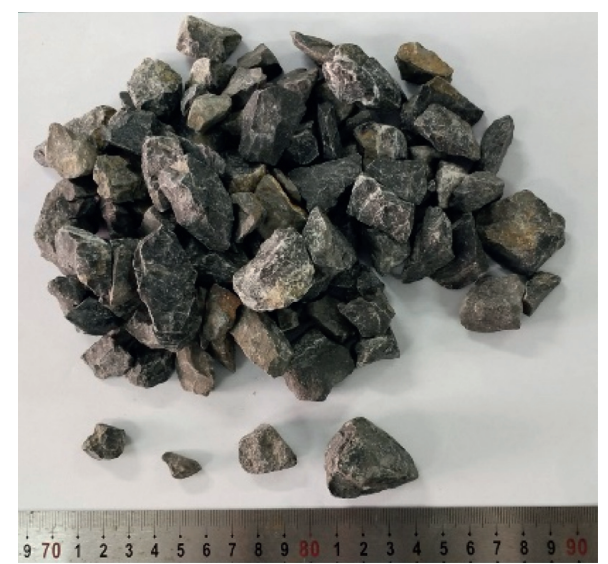

(a)

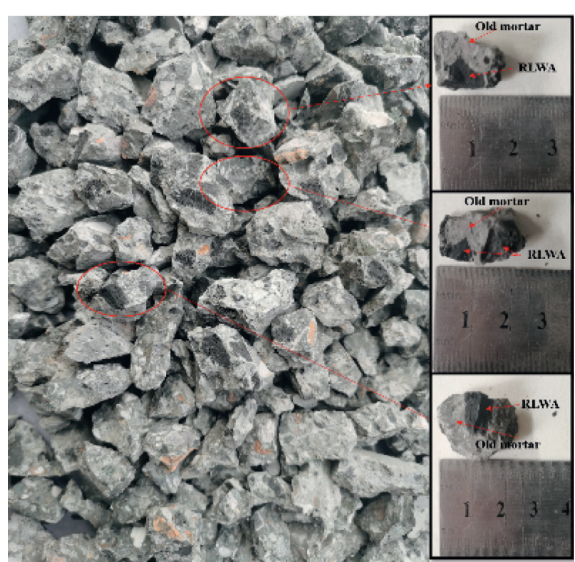

(b)

FIGURE 2: Coarse aggregate. (a) Natural coarse aggregate and (b) recycled lightweight coarse aggregate.

$150 \mathrm{~mm} \times 150 \mathrm{~mm} \times 150 \mathrm{~mm}$ were used to analyze the cubic compressive strength test. Furthermore, 15 prisms of size $150 \mathrm{~mm} \times 150 \mathrm{~mm} \times 300 \mathrm{~mm}$ were also employed for exploring the axial compression and stress-strain curves.

\section{Test Results and Analyses}

3.1. Dry Apparent Density. The studies have shown that the dry apparent density has a direct relationship with the compressive strength and replacement ratio of the specimens [34]. For different replacement ratios, 3 groups of cube specimens with dimensions of $100 \mathrm{~mm} \times 100 \mathrm{~mm} \times 100 \mathrm{~mm}$ were generated. After standard curing, the specimens were dried to a constant weight in an electric drying oven (SY1012) at $105{ }^{\circ} \mathrm{C}$, followed by the measurement of the quality. The measured dry apparent density under 0\%, 25\%, 50\%, 75\%, and $100 \%$ replacement ratio were $2353 \mathrm{~kg} / \mathrm{m}^{3}, 2200 \mathrm{~kg} / \mathrm{m}^{3}$,
$2085 \mathrm{~kg} / \mathrm{m}^{3}, 1839 \mathrm{~kg} / \mathrm{m}^{3}$, and $1705 \mathrm{~kg} / \mathrm{m}^{3}$, respectively. As can be observed, the dry apparent density of RLWAC is lower than that of ordinary concrete [34]. On enhancing the replacement ratio, the dry apparent density of RLWAC is noted to decrease gradually. Compared with a $0 \%$ replacement ratio, a decline of $6.50 \%, 11.39 \%, 21.84 \%$, and $27.54 \%$, respectively, is observed.

Based on the measured values of dry apparent density, the relationship between the dry apparent density and replacement ratio was fitted, as shown in Figure 3. As can be noted, the dry apparent density of the specimens exhibits a linear relationship with the replacement ratio. Using the replacement ratio as a variable, the functional relationship between the dry apparent density and the replacement ratio was fitted by using the principle of the least square method, and the obtained relation is shown in the following equation: 
TABLe 1: The basic physical property of coarse aggregate.

\begin{tabular}{|c|c|c|c|c|c|}
\hline Aggregate category & Grain size $(\mathrm{mm})$ & Bulk density $\left(\mathrm{kg} / \mathrm{m}^{3}\right)$ & Apparent density $\left(\mathrm{kg} / \mathrm{m}^{3}\right)$ & $\begin{array}{c}\text { Water absorption } \\
(\%)\end{array}$ & $\begin{array}{l}\text { Voidage } \\
(\%)\end{array}$ \\
\hline $\mathrm{Nat}$ & 5.00 & 1481.00 & 2500.00 & 0.62 & 40.76 \\
\hline Recycled lightweight coarse aggregate & $5.00-31.50$ & 776.00 & 1389.00 & 9.46 & 44.13 \\
\hline
\end{tabular}

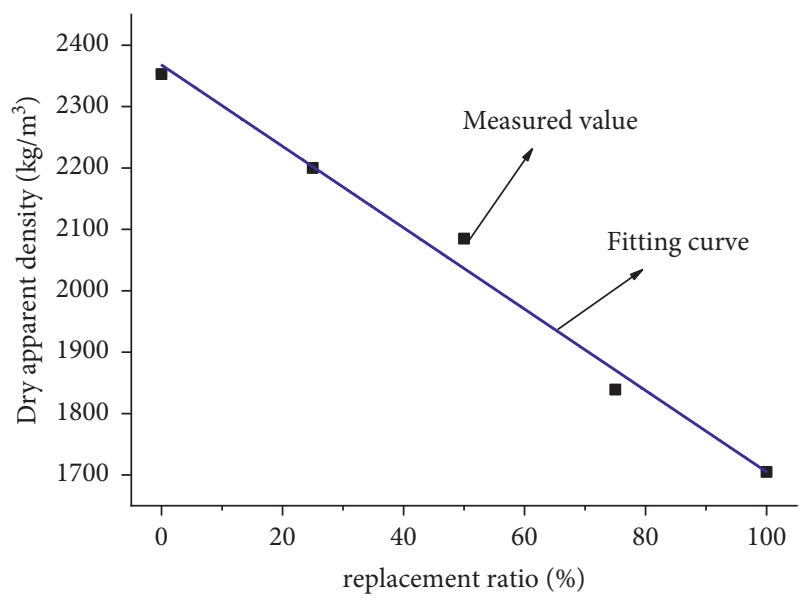

FIgURE 3: Relation curve between dry apparent density and replacement ratio.

$$
\begin{aligned}
y & =2367.8-662.8 \gamma \\
R^{2} & =0.98
\end{aligned}
$$

where the dry apparent density is expressed by $y$ and the replacement ratio of the recycled lightweight aggregate is denoted by $\gamma$.

3.2. Failure Mechanism and Failure Morphology. The failure mechanism of the RLWAC specimen is similar to that of the ordinary concrete specimen $[35,36]$. During the initial specimen loading, the surface of the specimen has no obvious change. As the load increases gradually, the internal stress of the specimen begins to increase. As the load continues to increase, the crackle sound representing the colloidal cracking is observed, and the internal cracks of the specimen continue to expand. Small cracks and microcracks appeared on the surface of the specimen, which gradually expanded and transfixed. As the load reaches the ultimate value, the specimen is eventually destroyed. However, the failure morphology of the RLWAC and ordinary concrete specimens is noted to be different. Ordinary concrete exhibits a quadrangular pyramid failure mode. Due to the porous and brittle characteristics of the RLWA, the cube specimens fail along the direction parallel to the crack. In prisms, the microcracks first appear on the surface, followed by expansion and transfixation. Finally, the specimen is damaged due to the massive blocky spalling. The failure morphology of the cube specimen is shown in Figures 4(a)-4(c), respectively. On the other hand, the failure morphology of the axial compression is shown in Figures $4(\mathrm{~d})$ 4(f), respectively. As can be observed, the failure region of RLWAC mainly exists in the interfacial transition zone between the mortar and RLWA.
3.3. Stress-Strain Curve. The compressive stress-strain curves of the specimens as a function of the replacement ratio are shown in Figure 5, with each curve obtained by averaging the whole curves of 3 prism specimens. The stress-strain curves of the RLWAC specimens with different replacement ratios are observed to be different. However, the curves generally comprise the ascending and descending segments with peak points. On increasing the RLWA replacement ratio, the stress at the peak point is noted to gradually decrease. For the same replacement ratio, the descending segment of the curve exhibits a steep trend in the beginning, followed by a levelling off, and the shape of the specific curve is noted to be significantly different without obvious regularity. The descending segment of the stress-strain curve is noted to be the steepest at $0 \%$ replacement ratio, while the descending segment is the gentlest at a replacement ratio of $50 \%$. Compared with the other replacement ratios, the specimen with $0 \%$ replacement ratio has higher strength and larger peak strain; thus, the curve is noted to be the steepest. On increasing the RLWA replacement ratio, the porosity and brittleness of RLWA become more significant, and the rate of decline of strength and peak strain becomes faster, comparatively. Further, the curve is noted to be gentle at $50 \%$ replacement ratio.

\section{Analysis of Influencing Factors}

4.1. Compressive Strength. The compressive performance of the RLWAC specimens is shown in Table 2. As can be observed, the cubic and axial compressive strength values decrease with increasing the replacement ratio.

Furthermore, it can be seen from Table 2 that the cubic and axial compressive strengths of the RLWAC specimens attain the design strength level, and the ratio of the axial 


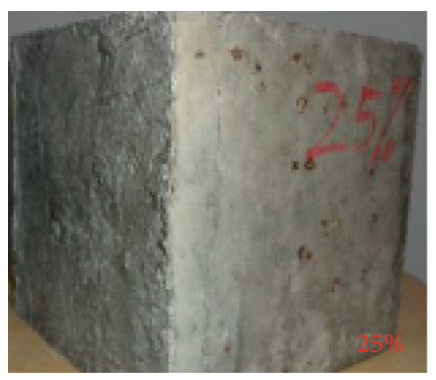

(a)

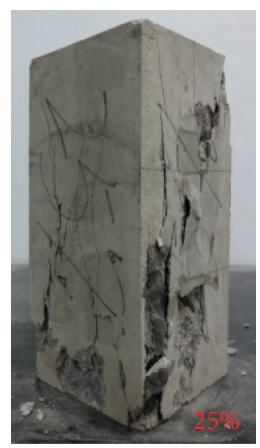

(d)

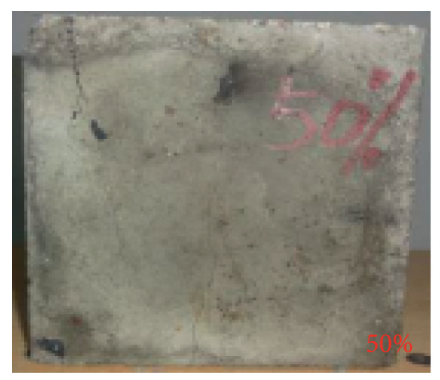

(b)

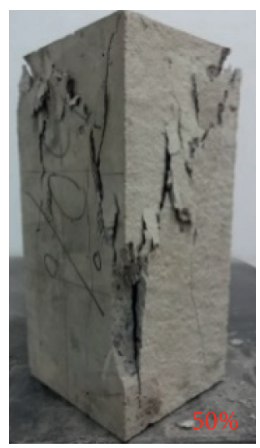

(e)

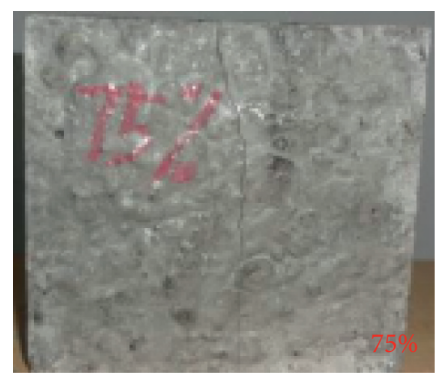

(c)

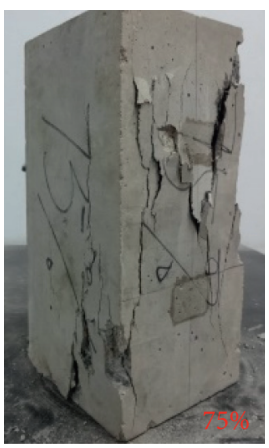

(f)

FigURE 4: Failure morphology for different replacement ratios. (a) $25 \%$ replacement ratio. (b) $50 \%$ replacement ratio. (c) $75 \%$ replacement ratio. (d) $25 \%$ replacement ratio. (e) $50 \%$ replacement ratio. (f) $75 \%$ replacement ratio.

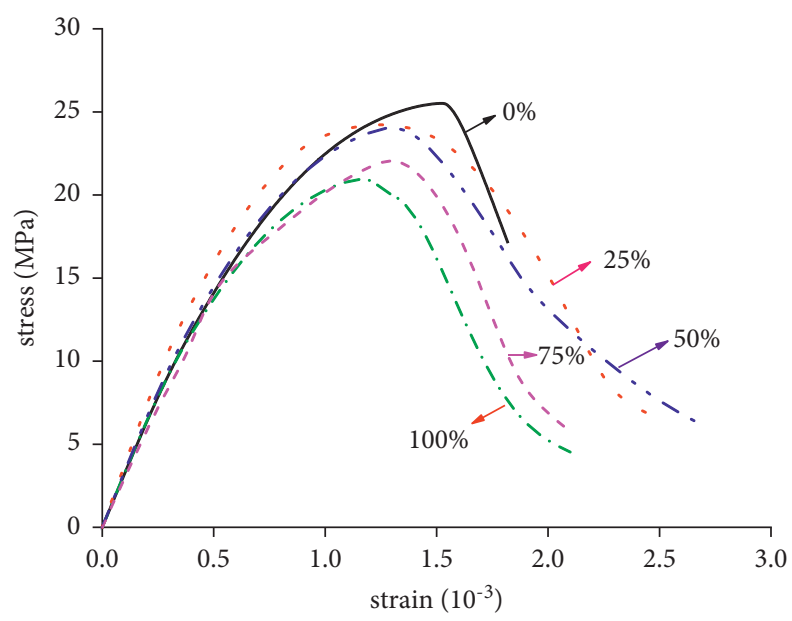

FIgURE 5: Stress-strain curves of recycled lightweight aggregate concrete.

compressive strength to the cubic compressive strength of the RLWAC is higher than that of ordinary concrete. However, at a replacement ratio of the RLWA of $100 \%$, the cubic compressive strength of the specimen is lower than the axial compressive strength. This is due to the reason that the coarse aggregate in RLWAC is composed of the RLWA, and the dry apparent density of the RLWAC reaches its minimum. Thus, due to the porous and brittle characteristics of the RLWA, the failure morphology of the cube specimen becomes close to that of the prism specimen, and the increment in the cubic compressive strength is limited. In addition, the discreteness of concrete also contributes to the observed phenomenon.
As shown in Figures 6 and 7, the compressive strength and replacement ratio of the RLWAC specimens reveal a linear progression, with the compressive strength of RLWAC being lower than that of ordinary concrete. On increasing the replacement ratio, the cubic and axial compressive strengths of the RLWAC specimens are observed to decrease gradually. The observed phenomenon is due to the numerous cracks and microcracks in the RLWA. On increasing the replacement ratio, the initial damage increases gradually at the macrolevel, and the strength decreases correspondingly. On increasing the replacement ratio, the cubic compressive strength is observed to decrease by $15.42 \%, 12.88 \%, 3.75 \%$, and $22.90 \%$, respectively, whereas 
TABLE 2: Compressive performance of recycled lightweight aggregate concrete.

\begin{tabular}{lccc}
\hline Replacement rate $(\%)$ & $f_{\mathrm{cu}}(\mathrm{MPa})$ & $f_{\mathrm{c}}(\mathrm{MPa})$ & \\
\hline 0 & 37.62 & 25.55 & $f_{\mathrm{c}} / f_{\mathrm{cu}}$ \\
25 & 31.82 & 24.76 & 0.68 \\
50 & 27.72 & 24.53 & 0.78 \\
75 & 26.68 & 22.54 & 0.88 \\
100 & 20.57 & 21.30 & 0.84 \\
\hline
\end{tabular}

Note. The cubic compressive strength is expressed by $f_{\mathrm{cu}}$. The axial compressive strength is expressed by $f_{\mathrm{c}}$.

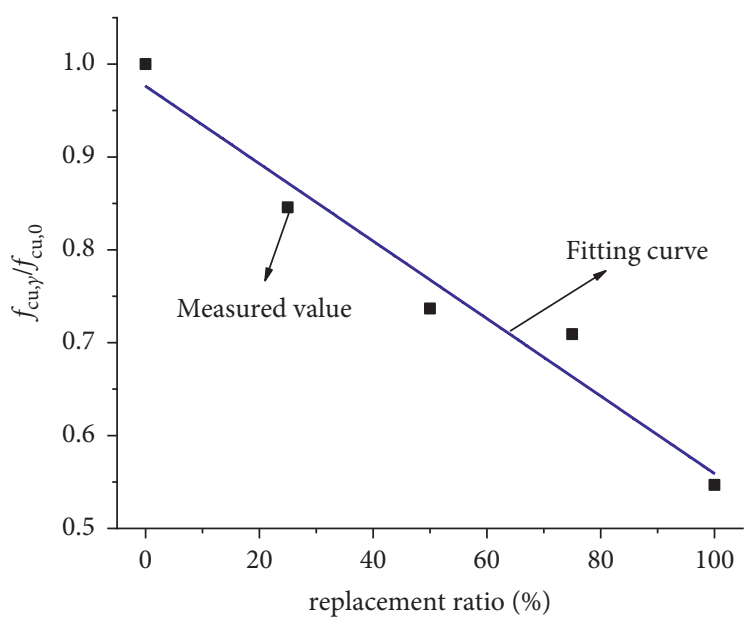

Figure 6: Fitting curve of $f_{\mathrm{cu}, \gamma} / f_{\mathrm{cu}, 0}$ and replacement ratio.

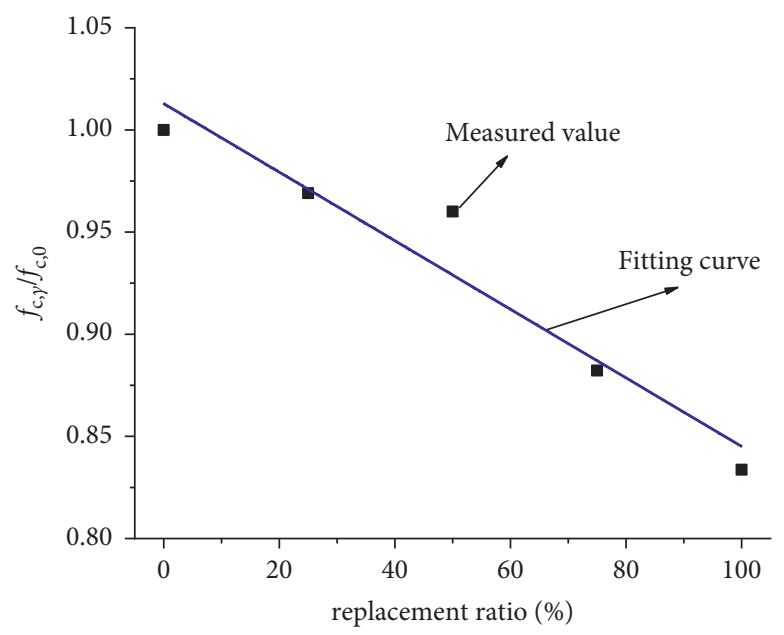

Figure 7: Fitting curve of $f_{\mathrm{c}, \gamma} / f_{\mathrm{c}, 0}$ and replacement ratio.

the axial compressive strength declines by $3.09 \%, 0.93 \%$, $8.11 \%$, and $5.50 \%$, respectively. As the replacement ratio of the RLWA changes from $50 \%$ to $75 \%$, the cubic compressive strength does not change significantly. Furthermore, as the replacement ratio of the RLWA changes from $25 \%$ to $50 \%$, the axial compressive strength changes insignificantly. Compared with natural aggregate, RLWA has the characteristics of porosity and brittleness. On increasing the RLWA replacement ratio, the compressive strength of the specimen decreases gradually. As the replacement ratio changes from $0 \%$ to $25 \%$ and $75 \%$ to $100 \%$, the effect of RLWA content compared with the replacement ratio on the compressive strength is more significant, thus resulting in a more obvious decline in the compressive strength.

Based on the measured values in Table 2, the compressive strength of the specimens was subjected to the dimensionless fitting process, as shown in Figures 6 and 7. As can be observed, the compressive strength of the RLWAC specimens reveals a linear relationship with the replacement ratio of the RLWA. Under the condition of solely changing the replacement ratio and using the least squares method, the obtained relations are shown as follows: 


$$
\begin{array}{ll}
\frac{f_{c u, \gamma}}{f_{c u, 0}}=-0.42 \gamma+0.98 & R^{2}=0.96 \\
\frac{f_{c, \gamma}}{f_{c, 0}}=-0.17 \gamma+1.01 & \mathrm{R}^{2}=0.93
\end{array}
$$

where $f_{\mathrm{cu},} \gamma$ and $f_{\mathrm{c}, \gamma}$ represent the cubic and axial compressive strengths as a function of the replacement ratio, respectively. Furthermore, $f_{\mathrm{cu}, 0}$ and $f_{\mathrm{c}, 0}$ represent the cubic and axial compressive strengths of the RLWAC specimens at a replacement ratio of $0 \%$.

4.2. Peak Strain. The peak strain $\left(\varepsilon_{0}\right)$ of RLWAC is shown in Table 3. As can be observed, the peak strain decreases gradually on increasing the RLWA replacement ratio, and the relationship is noted to be largely linear. This is due to the reason that the elastic modulus of RLWAC exhibits a little difference for different replacement ratios before reaching the peak strain. Furthermore, the axial compressive strength of RLWAC decreases with increasing the replacement ratio of the RLWA, i.e., the peak stress decreases gradually and the degree of decline is more obvious. Therefore, the corresponding peak strain of RLWAC decreases by increasing the replacement ratio of the RLWA.

As the replacement ratio of the RLWA is increased from $0 \%$ to $25 \%$, the peak strain of the specimen decreases by $2.9 \%$. As the replacement ratio of the RLWA increases from $25 \%$ to $50 \%$, the peak strain is decreased by $5.6 \%$. Furthermore, as the replacement ratio of the RLWA is enhanced from $50 \%$ to $75 \%$, the peak strain is noted to decrease by $3.5 \%$. Finally, as the replacement ratio of the RLWA increases from $75 \%$ to $100 \%$, the peak strain is decreased by $6.8 \%$.

The relationship between the peak strain and the replacement ratio is shown in Figure 8. As can be observed, the peak strain of the specimens shows a linear trend with the replacement ratio. Under the condition of solely changing the replacement ratio, the obtained fitting relation is shown as follows:

$$
\varepsilon_{0}=-0.27 \gamma+1.55 \quad \mathrm{R}^{2}=0.98
$$

4.3. Ultimate Strain. The strain at $0.5 f_{\mathrm{c}}$ in the descending segment of the stress-strain curve is taken as the ultimate strain $\left(\varepsilon_{u}\right)$, and the ultimate strain of the RLWAC specimens as a function of the replacement ratio is shown in Table 4. The ultimate strain has not been measured at a replacement ratio of $0 \%$. This is due to the reason that the stiffness of the specimen is large at a replacement ratio of $0 \%$, while the stiffness of the test machine is somewhat insufficient. This leads to a sudden failure of the specimen, thus rendering the measured data of the descending segment as discrete and inaccurate. On enhancing the replacement ratio of the RLWA, the ultimate strain of the specimens decreases gradually, which is determined by the internal structure of the RLWA. The RLWA possesses numerous pores and brittle behavior, and the RLWAC specimen prepared by using the
RLWA exhibits an obvious sudden decline in the macro. On enhancing the replacement ratio of the RLWA, the plastic capacity of the descending segment in the stress-strain curves decreases gradually. Correspondingly, the ultimate strain, a quantitative indicator of plasticity, also decreases immediately.

As the replacement ratio of the RLWA in the specimen increases from $50 \%$ to $75 \%$, the ultimate strain is observed to decrease the most, by about $14.2 \%$. Furthermore, as the replacement ratio of the RLWA increases from $25 \%$ to $50 \%$ and from $75 \%$ to $100 \%$, the ultimate strain is noted to decrease by about $3 \%$. It can be observed that the ultimate strain of the RLWAC specimens varies significantly with the replacement ratio at a replacement ratio value of $50 \%$.

The relationship between the ultimate strain and the replacement ratio is shown in Figure 9. It can be seen that the ultimate strain of the specimens shows a linear increasing trend with the replacement ratio. Under the condition of solely changing the replacement ratio, the obtained fitting formula is shown as follows:

$$
\varepsilon_{u}=-0.61 \gamma+2.28 \quad \mathrm{R}^{2}=0.88
$$

4.4. Conversion Relation of Compressive Strength. For ordinary concrete, the conversion relationship between the axial and cubic compressive strengths is shown as follows [37]:

$$
\frac{f_{\mathrm{c}}}{f_{\mathrm{cu}}}=0.76 \text {. }
$$

As the determination of the mechanical properties of the RLWA and ordinary aggregate is different, the conversion relationship of the compressive strength of the ordinary concrete is no longer applicable to RLWAC. As shown in Table 2, the ratio of the axial compressive strength to the cubic compressive strength in the RLWAC specimens is closely related to the replacement ratio of the RLWA. Based on the measured values, the relationship between the ratio of the axial compressive strength to the cube compressive strength of RLWAC and replacement ratio was subjected to fitting, as shown in Figure 10, and the functional relationship is shown as follows:

$$
y=-0.31 \gamma+0.69 \quad \mathrm{R}^{2}=0.81
$$

\section{Stress-Strain Equation}

To further explore the stress-strain behavior of RLWAC and its relationship with the replacement ratio of the RLWA, the stress-strain relationship was subjected to the dimensionless fitting processing, as shown in Figure $11\left(\sigma_{0}\right.$ is the peak stress, i.e., axial compressive strength).

As shown in Figure 11, the ascending and descending segments of the curve exhibit a large difference. In order to obtain a more accurate stress-strain equation, the model proposed by Guo [37] was used for attaining the piecewise fitting, as shown in equation (7). 
TABLE 3: Peak strain of recycled lightweight aggregate concrete.

\begin{tabular}{lccccc}
\hline Replacement ratio (\%) & 0 & 25 & 50 & 75 & 100 \\
\hline Peak strain $\left(\times 10^{6}\right)$ & 1538 & 1494 & 1410 & 1360 & 1267 \\
\hline
\end{tabular}

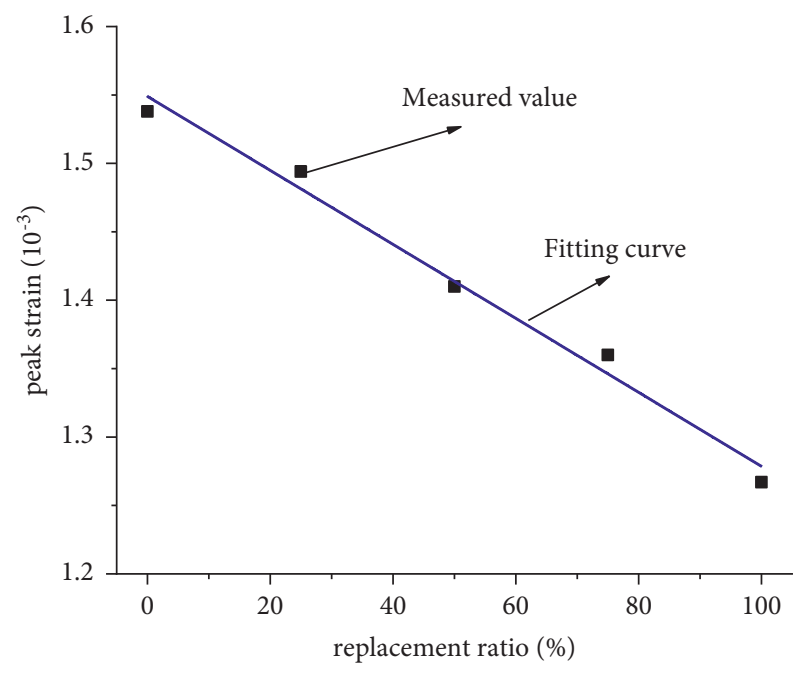

Figure 8: Different replacement ratios of peak strain fitting curves.

TABLE 4: Ultimate strain of recycled lightweight aggregate concrete.

\begin{tabular}{lccccc}
\hline Replacement ratio $(\%)$ & 0 & 25 & 50 & 75 & 100 \\
\hline Ultimate strain $\left(\times 10^{6}\right)$ & - & 2103 & 2037 & 1747 & 1689 \\
\hline
\end{tabular}

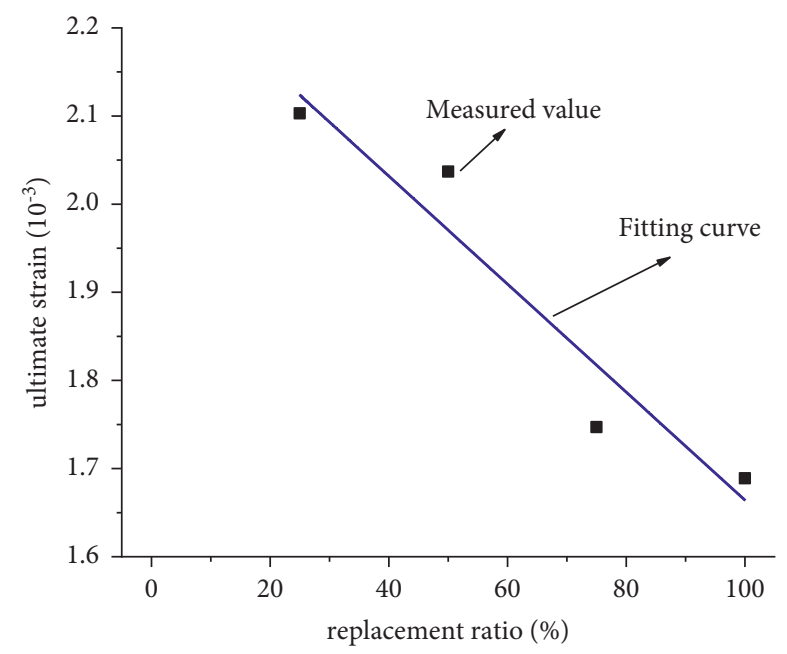

FIGURE 9: Different replacement ratios of ultimate strain fitting curves.

$$
y=\left\{\begin{array}{ll}
\alpha_{\mathrm{a}} x+\left(3-2 \alpha_{\mathrm{a}}\right) x^{2}+\left(\alpha_{\mathrm{a}}-2\right) x^{3} & 0 \ll x<1 \\
\frac{x}{\alpha_{\mathrm{d}}(x-1)^{2}+x} & x \gg 1
\end{array},\right.
$$

where $x$ represents the abscissa variable $\varepsilon / \varepsilon_{0}$, whereas $y$ represents the ordinate variable $\sigma / \sigma_{0}$.
The measured values have been fitted by the least square method, and the coefficients $\alpha_{\mathrm{a}}$ and $\alpha_{\mathrm{d}}$ as a function of the replacement ratio of the RLWA are shown in Table 5. The relation curve of $\alpha_{\mathrm{a}}, \alpha_{\mathrm{d}}$, and $\gamma$ is presented in Figure 12.

In order to obtain an equation involving the parameters $\alpha_{\mathrm{a}}$ and $\alpha_{\mathrm{d}}$ with respect to the replacement ratio, the 


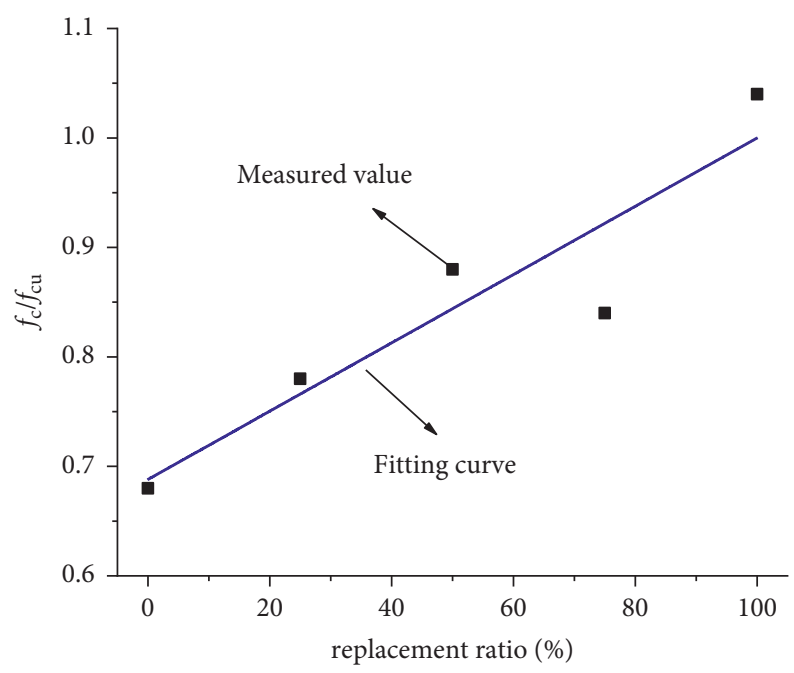

Figure 10: Different replacement ratios of $f_{\mathrm{c}} / f_{\mathrm{cu}}$ fitting curves.

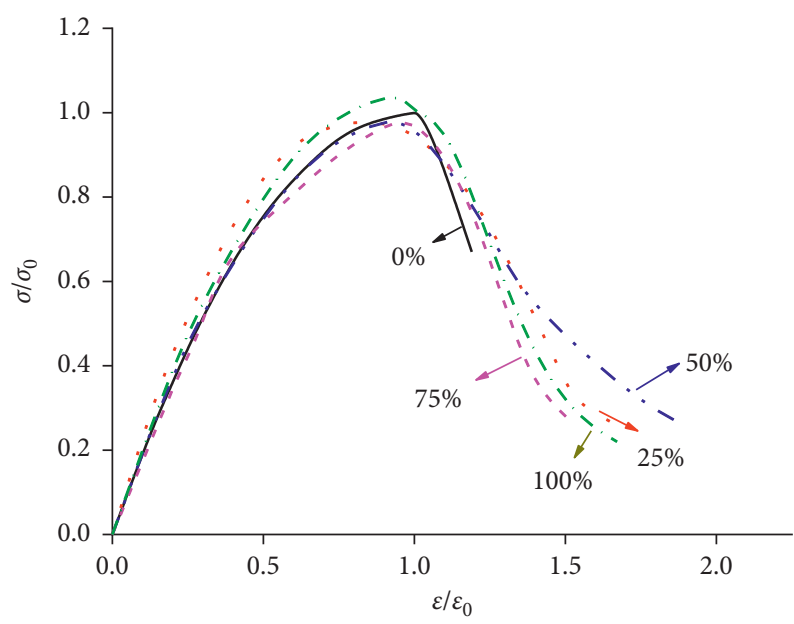

FIGURE 11: Dimensionless stress-strain curve of recycled lightweight aggregate concrete.

TABle 5: Coefficients $\alpha_{a}$ and $\alpha_{d}$.

\begin{tabular}{lccccc}
\hline$\gamma(\%)$ & 0 & 25 & 50 & 75 & 100 \\
\hline$\alpha_{\mathrm{a}}$ & 2.06 & 2.68 & 2.08 & 1.97 & 2.36 \\
$\alpha_{\mathrm{d}}$ & 16.20 & 9.27 & 7.51 & 13.70 & 11.60 \\
\hline
\end{tabular}

relationship between the parameters $\alpha_{\mathrm{a}}$ or $\alpha_{\mathrm{d}}$ and the replacement ratio of the RLWA can be obtained by analyzing and fitting the data obtained in Table 5, as shown in the following equations:

$$
\begin{array}{ll}
\alpha_{\mathrm{a}}=2.2+0.4 \sin 7.0 \gamma & \mathrm{R}^{2}=0.86 \\
\alpha_{\mathrm{d}}=11.0+4.3 \cos 7.5 \gamma & \mathrm{R}^{2}=0.95
\end{array}
$$




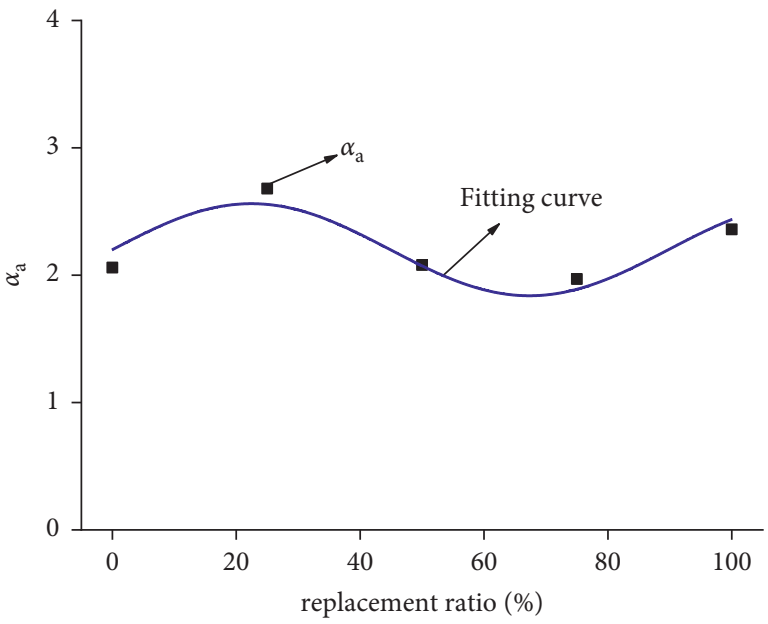

(a)

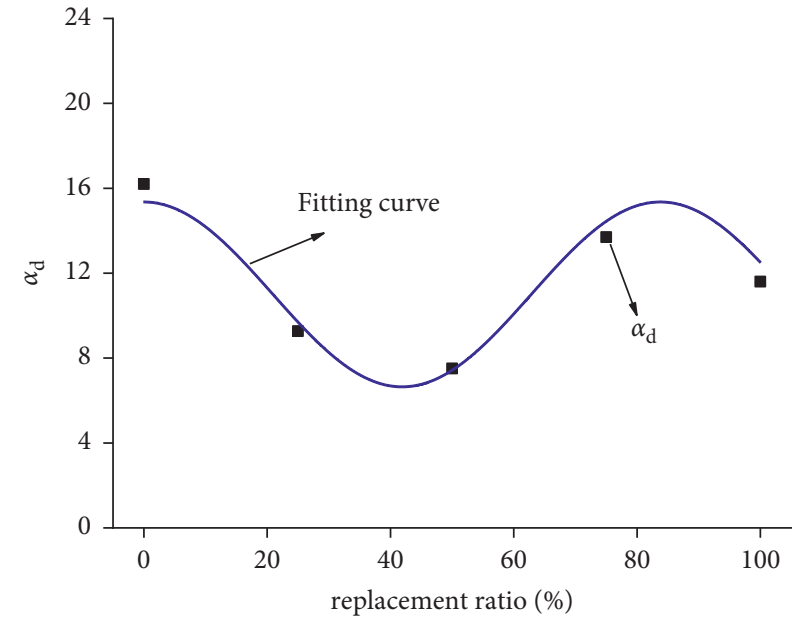

(b)

Figure 12: The relation curve of $\alpha_{a}, \alpha_{d}$, and $\gamma$. (a) Fitting curve of $\alpha_{\mathrm{a}}$ and replacement ratio. (b) Fitting curve of $\alpha_{\mathrm{d}}$ and replacement ratio.

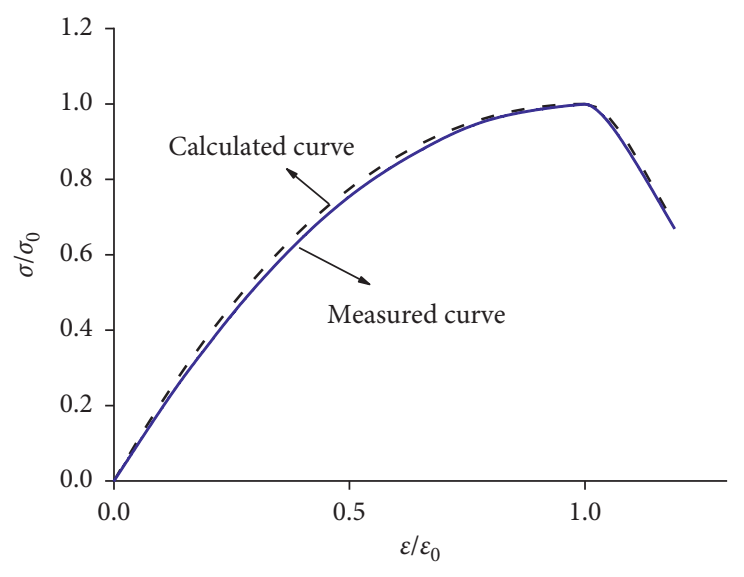

(a)

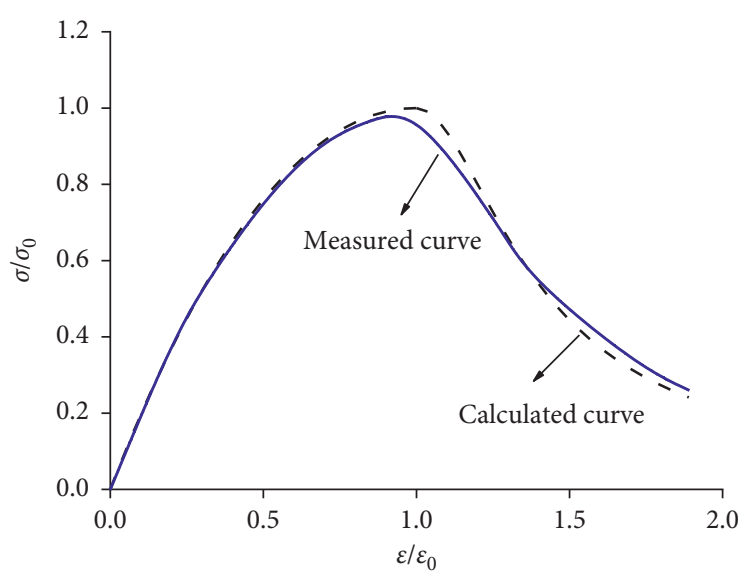

(c)

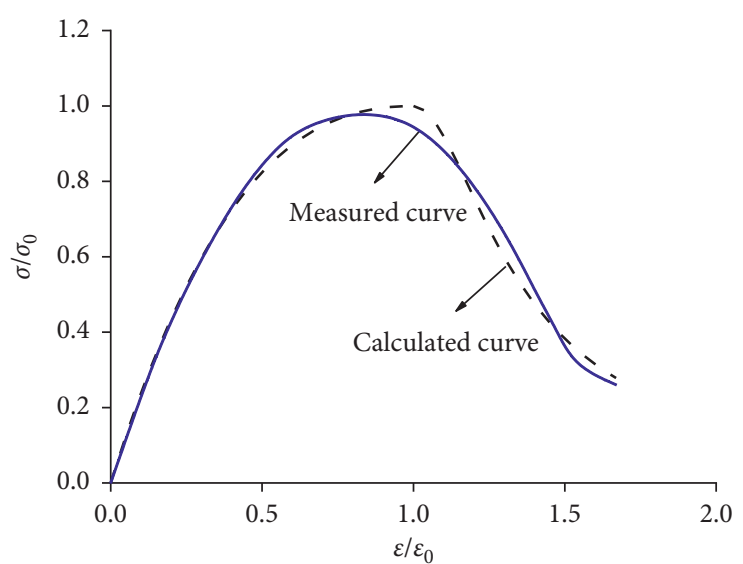

(b)

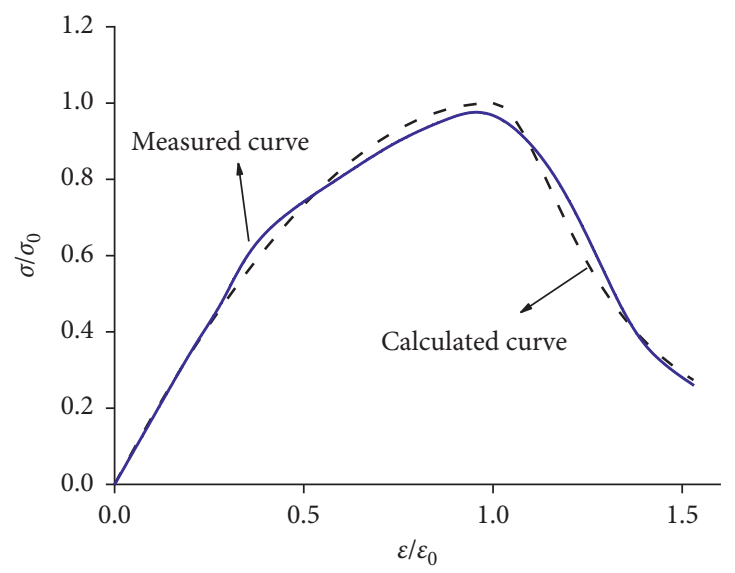

(d)

FIGURE 13: Continued. 


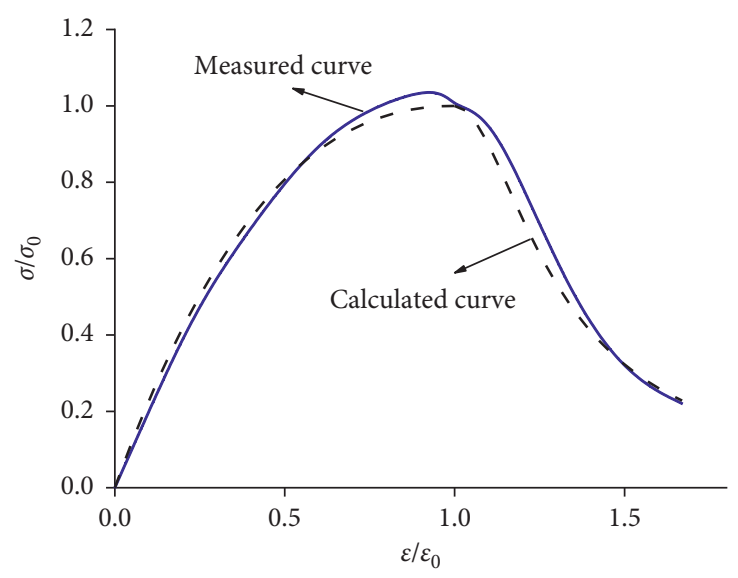

(e)

FiguRE 13: Comparison of the measured and calculated stress-strain curves. (a) $\gamma=0 \%$. (b) $\gamma=25 \%$. (c) $\gamma=50 \%$. (d) $\gamma=75 \%$. (e) $\gamma=100 \%$.

Taking $\gamma=0 \%, 25 \%, 50 \%, 75 \%$, and $100 \%$ in equations (9) and (10), the values of $\alpha_{\mathrm{a}}$ and $\alpha_{\mathrm{d}}$ are calculated and substituted in equation (8). The comparison of the measured and calculated curves as a function of the replacement ratio is presented in Figure 13.

\section{Conclusions}

In this study, the compressive mechanical properties of 15 cube and 30 prism specimens were studied, and the influence of the replacement ratios of the RLWA on the compressive strength, peak stress, peak strain, and other performance indices of RLWAC was explored. The main conclusions can be drawn as follows:

(1) The dry apparent density of the RLWAC specimens decreases with increasing the RLWA replacement ratio. Compared with a $0 \%$ replacement ratio, the decline is observed to be $6.50 \%, 11.39 \%, 21.84 \%$, and $27.54 \%$. Furthermore, the cubic compressive strength of RLWAC increases with the dry apparent density.

(2) The cubic specimen fails along the direction parallel to the crack, which is not consistent with the quadrangular pyramid failure observed in the case of ordinary concrete. The failure morphology of the RLWAC prisms is noted to be similar to that of ordinary concrete. Specifically, the upper and lower penetrating cracks are formed, and the angle between the cracks and the horizontal plane ranges from $60^{\circ}$ to $80^{\circ}$.

(3) As compared with ordinary concrete, the cubic compressive strength, axial compressive strength, peak strain, and ultimate strain of RLWAC are noted to be lower. Furthermore, these quantities are observed to gradually decrease with increasing the RLWA replacement ratio. Specifically, as the replacement ratio increases from $75 \%$ to $100 \%$, the peak strain decreases the most by about $6.8 \%$. On the other hand, as the replacement ratio increases from $50 \%$ to $75 \%$, the ultimate strain decreases the most by about $14.2 \%$.

(4) Based on the influence of the replacement ratio on the cubic compressive strength, axial compressive strength, and other axial compressive performance indices, the functional relationships of the strength indices and the conversion values of each strength index with the replacement ratio have been established.

(5) The stress-strain curves of the RLWAC specimens with different replacement ratios are noted to be different. The curves are generally comprised of the ascending and descending segments, with the replacement ratios significantly influencing the curve shape and trend. Based on the model proposed by Guo Z.H., the stressstrain equation of RLWAC could also be established, and the fitting results were observed to be in good agreement with the test results.

\section{Data Availability}

The data used to support the findings of this study are included within the article.

\section{Conflicts of Interest}

The authors declare that they have no conflicts of interest.

\section{Acknowledgments}

This work was financially supported by Fundamental Research Funds for the Central Universities (XDJK2020C028), Experimental Technology Research Project of Southwest University (SYJ2020027), the Key R\&D and Promotion Projects in Henan Province (212102310288), and the Fundamental Research Funds for the Universities of Henan Province (NSFRF200320). 


\section{References}

[1] X. G. Zhang, X. Gao, X. G. Wang, E. C. Meng, and F. Wang, "Axial compression performance of basalt-fiber-reinforced recycled-concrete-filled square steel tubular stub column," Advances in Concrete Construction, vol. 10, no. 6, pp. 559-571, 2020.

[2] B. Monalisa, S. K. Bhattacharyya, A. K. Minocha, R. Deoliya, and S. Maiti, "Recycled aggregate from $C \& D$ waste \& its use in concrete -A breakthrough towards sustainability in construction sector: a review," Construction and Building Materials, vol. 68, pp. 501-516, 2014.

[3] I. Marie and H. Quiasrawi, "Closed-loop recycling of recycled concrete aggregates," Journal of Cleaner Production, vol. 37, pp. 243-248, 2012.

[4] J. Z. Xiao, Y. J. Huang, and Z. H. Sun, "Seismic Behavior of recycled aggregate concrete filled steel and glass fiber reinforced plastic tube columns," Advances in Structural Engineering, vol. 17, no. 5, pp. 693-707, 2014.

[5] B. Wu, X.-Y. Zhao, and J.-S. Zhang, "Cyclic behavior of thinwalled square steel tubular columns filled with demolished concrete lumps and fresh concrete," Journal of Constructional Steel Research, vol. 77, pp. 69-81, 2012.

[6] K. H. Younis, A. A. Amin, H. G. Ahmed, and S. M. Maruf, "Recycled aggregate concrete including various contents of metakaolin: mechanical behavior," Advances in Materials Science and Engineering, vol. 2020, pp. 1-17, Article ID 8829713, 2020.

[7] S. P. Zhang and L. Zong, "Properties of concrete made with recycled coarse aggregate from waste brick," Environmental Progress \& Sustainable Energy, vol. 33, no. 4, pp. 1283-1289, 2014.

[8] T. Ozbakkaloglu, A. Gholampour, and T. Y. Xie, "Mechanical and durability properties of recycled aggregate concrete: effect of recycled aggregate properties and content," Journal of Materials in Civil Engineering, vol. 30, no. 2, Article ID 04017275, 2018.

[9] C. J. Shi, Y. K. Li, J. K. Zhang, W. G. Li, L. L. Chong, and Z. B. Xie, "Performance enhancement of recycled concrete aggregate - a review," Journal of Cleaner Production, vol. 112, pp. 466-472, 2016.

[10] C. Thomas, J. D. Brito, A. Cimentada, and J. A. Sainz-Aja, "Macro- and micro- properties of multi-recycled aggregate concrete," Journal of Cleaner Production, vol. 245, Article ID $118843,2020$.

[11] C. S. Das, T. Dey, R. Dandapat, B. B. Mukharjee, and J. Kumar, "Performance evaluation of polypropylene fibre reinforced recycled aggregate concrete," Construction and Building Materials, vol. 189, pp. 649-659, 2018.

[12] M. Wijayasundara, P. Mendis, and R. H. Crawford, "Integrated assessment of the use of recycled concrete aggregate replacing natural aggregate in structural concrete," Journal of Cleaner Production, vol. 174, pp. 591-604, 2018.

[13] T. Yanweerasak, T. M. Kea, H. Ishibashi, and M. Akiyama, "Effect of recycled aggregate quality on the bond behavior and shear strength of RC members," Applied Sciences-Basel, vol. 8, no. 11, Article ID 2054, 2018.

[14] C. H. Zhou and Z. P. Chen, "Mechanical properties of recycled concrete made with different types of coarse aggregate," Construction and Building Materials, vol. 134, pp. 497-506, 2017.

[15] Y. C. Guo, J. H. Zhang, G. Chen, G. M. Chen, and Z. H. Xie, "Fracture behaviors of a new steel fiber reinforced recycled aggregate concrete with crumb rubber," Construction and Building Materials, vol. 53, pp. 32-39, 2014.

[16] K. Pandurangan, A. Dayanithy, and S. Om Prakash, "Influence of treatment methods on the bond strength of recycled aggregate concrete," Construction and Building Materials, vol. 120, pp. 212-221, 2016.

[17] S. Medjigbodo, A. Z. Bendimerad, E. Rozière, and A. Loukili, "How do recycled concrete aggregates modify the shrinkage and self-healing properties?" Cement and Concrete Composites, vol. 86, pp. 72-86, 2018.

[18] X. Y. Zhu, X. D. Chen, N. Shen, H. X. Tian, X. Q. Fan, and J. Lu, "Mechanical properties of pervious concrete with recycled aggregate," Computers and Concrete, vol. 21, no. 6, pp. $623-635,2018$.

[19] S. Mesgari, A. Akbarnezhad, and J. Z. Xiao, "Recycled geopolymer aggregates as coarse aggregates for portland cement concrete and geopolymer concrete: effects on mechanical properties," Construction and Building Materials, vol. 236, Article ID 117571, 2020.

[20] C. Thomas, J. Setién, J. A. Polanco, A. I. Cimentada, and C. Medina, "Influence of curing conditions on recycled aggregate concrete," Construction and Building Materials, vol. 172, pp. 618-625, 2018.

[21] C. C. Zheng, C. Lou, G. Du, X. Z. Li, Z. W. Liu, and L. Q. Li, "Mechanical properties of recycled concrete with demolished waste concrete aggregate and clay brick aggregate," Results in Physics, vol. 9, pp. 1317-1322, 2018.

[22] R. V. Silva, J. De Brito, and R. K. Dhir, "Fresh-state performance of recycled aggregate concrete: a review," Construction and Building Materials, vol. 178, pp. 19-31, 2018.

[23] J. F. Liang, E. Wang, X. Zhou, and Q.-L. Le, "Influence of high temperature on mechanical properties of concrete containing recycled fine aggregate," Computers and Concrete, vol. 21, no. 1, pp. 87-94, 2018.

[24] H. K. Wu, C. W. Liu, S. Shi, and K. L. Chen, "Experimental research on the physical and mechanical properties of concrete with recycled plastic aggregates," Journal of Renewable Materials, vol. 8, no. 7, pp. 727-738, 2020.

[25] C. Goksu, I. Saribas, E. Binbir, Y. Akkaya, and A. Ilki, "Structural performance of recycled aggregates concrete sourced from low strength concrete," Structural Engineering \& Mechanics, vol. 69, no. 1, pp. 77-93, 2019.

[26] A. Wongkvanklom, P. Posi, B. Khotsopha et al., "Structural lightweight concrete containing recycled lightweight concrete aggregate," Ksce Journal of Civil Engineering, vol. 22, no. 8, pp. 3077-3084, 2018.

[27] L. M. Huang, Z. H. Yang, Z. Li, Y. F. Xu, and L. Yu, "Recycling of the end-of-life lightweight aggregate concrete (LWAC) with a novel approach," Journal of Cleaner Production, vol. 275, Article ID 123099, 2020.

[28] J. A. Bogas, J. de Brito, and J. M. Figueiredo, "Mechanical characterization of concrete produced with recycled lightweight expanded clay aggregate concrete," Journal of Cleaner Production, vol. 89, pp. 187-195, 2015.

[29] J. A. Bogas, J. de Brito, and J. Cabaço, "Long-term behaviour of concrete produced with recycled lightweight expanded clay aggregate concrete," Construction and Building Materials, vol. 65, pp. 470-479, 2014.

[30] S. M. S. Kazmi, M. J. Munir, and Y. F. Wu, "Application of waste tire rubber and recycled aggregates in concrete products: a new compression casting approach," Resources, Conservation and Recycling, vol. 167, Article ID 105353, 2021.

[31] M. J. Munir, S. M. S. Kazmi, Y. F. Wu, I. Patnaikuni, J. F. Wang, and Q. Wang, "Development of a unified model to 
predict the axial stress-strain behavior of recycled aggregate concrete confined through spiral reinforcement," Engineering Structures, vol. 218, Article ID 110851, 2020.

[32] J. Y. Wang, K. Zheng, N. Cui et al., "Green and durable lightweight aggregate concrete: the role of waste and recycled materials," Materials, vol. 13, no. 13, Article ID 3041, 2020.

[33] M. Abd Elrahman, S.-Y. Chung, and D. Stephan, "Effect of different expanded aggregates on the properties of lightweight concrete," Magazine of Concrete Research, vol. 71, no. 2, pp. 95-107, 2019.

[34] A. Ambroziak and P. Ziolkowski, "Concrete compressive strength under changing environmental conditions during placement processes," Materials, vol. 13, no. 20, Article ID 4577, 2020.

[35] J. Y. Yoon and J. H. Kim, "Mechanical properties of preplaced lightweight aggregates concrete," Construction and Building Materials, vol. 216, pp. 440-449, 2019.

[36] Y. Ren, Z. P. Yu, Q. Huang, and Z. Ren, "Constitutive model and failure criterions for lightweight aggregate concrete: a true triaxial experimental test," Construction and Building Materials, vol. 171, pp. 759-769, 2018.

[37] Z. H. Guo, The Strength and Deformation of concreteExperimentalresults and Constitutive RelationshipTsinghua University Press, Beijing, China, 1997. 